\title{
Chapter 3 \\ ACCURACY OF HYDROGRAPHIC SURVEYING IN AND NEAR THE SURF ZONE
}

\author{
Thorndike Saville, Jr., and Joseph M. Caldwell \\ respectively, Research Engineer, Research Division, \\ and Chief, Research Division, Beach Erosion Board, \\ Department of the Army, Washington, D. C.
}

\section{INTRODUC TION}

The analysis and solution of most beach erosion problems are based to a significant degree on the quantitative changes in the bottom hydrography as observed in successive surveys. Critical decisions as to the dominant direction of littoral drift, the average rate of this drift, and the onshore-offshore movement of material are based largely on such hydrographic surveys. As the net changes between successive surveys are usually small compared to the area being studied, the degree of accuracy or comparability of the hydrographic surveys is of considerable importance. For instance, a net change of 100,000 cubic yards over one square mile of beach represents an average change in depth of only about 0.1 feet. Thus, it can be seen that uncompensated errors in depth measurement of as little as 0.1 feet can produce indications of significant littoral aand movement which might not exist in reality.

The errors involved in hydrographic work may be attributed almost entirely to two different causes. The first of these, a sounding error, results from errors inherent in the sounder and the methods involved in reducing the sounder data to an actual bottom profile (i.e. tide corrections, elimination of the effect of waves, water temperature corrections, etc.). The second, a spacing error, results from the fact that a particular profile may not be entirely representative of its assigned section of beach.

The sounding error is a measure of the accuracy (or inaccuracy) with which the profile deduced from the sounder record actualiy represents the bottom hydrography along the particular range being sounded; as such it may be determined as a function of the reproducibility of this profile by the repetition of a series of soundings. The spacing error is a measure of the accuracy (or inaccuracy) with which the particular profile portrays the characteristics of the contiguous beach area; as such it may be determined as a function of the reproducibility of the hydrography of a beach area by using various spacings between adjacent profiles.

It was the purpose of this study to determine on a statistical basis the degree of accuracy that could be expected in hydrographic survey work where comparability of successive surveys is a prime consideration. Tests to determine the magnitude of these two types of error were made at Mission Beach, California. Mission Beach is a relatively long, straight beach, with essentially parallel contours, and no radical changes of bottom hydrography along its length, and as such, is representative of many of the southern California beaches. The results of these tests may 


\section{COASTAL ENGINEERING}

be expected to apply to other beaches of the same type.

The tests were made under normal operating conditions by the Field Research Group of the Beach Erosion Board; i.e., standard Beach Erosion Board procedures were used in checking the tide, the sounding instruments, and the position of the survey boat so that the results could be considered applicable to actual hydrographic surveys made by the Field Group. A description of the standard survey techniques used by the Field Research Group is given in The Bulletin of the Beach Erosion Board, July 1947.

\section{DETERMINATION OF THE SOUNDING ERROR}

\section{DESCRIPTION OF TEST}

The test to determine sounding error involved the repeated sounding of a single profile eight times successively in a five-hour period. The survey extended from the shore line to the -50-foot mean lower low water contour on Beach Erosion Board profile range 136 at Mission Bay, California. This range is about 5500 feet north of the Mission Bay jetties and the -50-foot contour is about 4250 feet offshore. The $r$ ange was established by the Field Research Group in connection with other work in the area. The test was made on 3 November 1950 while swells of about two feet in height were running. The tide variation was 0.4 feet during the 5-hour period; corrections of the sounding records were made for this variation. An amphibious truck, DUKW, was used as the floating equipment for the survey. In making the tests, a Bludworth NK-2 echo sounder was used while the DUKW was floating; a lead line was used while the wheels of the DUKW were grounded in traversing the shallow water section of the profile.

\section{ANALYSIS OF ECHO SOUNDER DATA}

The echo-sounder data and the lead-line soundings were analyzed separately. The echo-sounder charts were first corrected for tide elevation and the soundings taken of $f$ at 250-foot intervals starting at a point 750 feet from the base line. The tabulation of results is showr. on Table 1. This table shows the corrected soundings for the eight test runs and covers the area from about the -7 -foot to the -50 -foot mean lower low water contour, a distance of about 3500 feet. The table also shows an "average" profile column obtained by averaging the eight separate profiles.

As with most statistical data, there are several ways of effecting an analysis. However, only two methods appeared to have enough engineering significance in the present case to warrant a set of calculations. The first method assumes that the "average" profile is the correct profile for the 5-hour period and then studies the deviation of each of the eight profiles from the average. The second method assumes that the deviation of one profile from the succeeding profile is a better measurement of the degree of accuracy with which successive surveys can be compared. The data has been analysed in both ways. 
ACCURACY OF HYDROGRAPHIC SURVEYING IN AND NEAR THE SURF ZONE
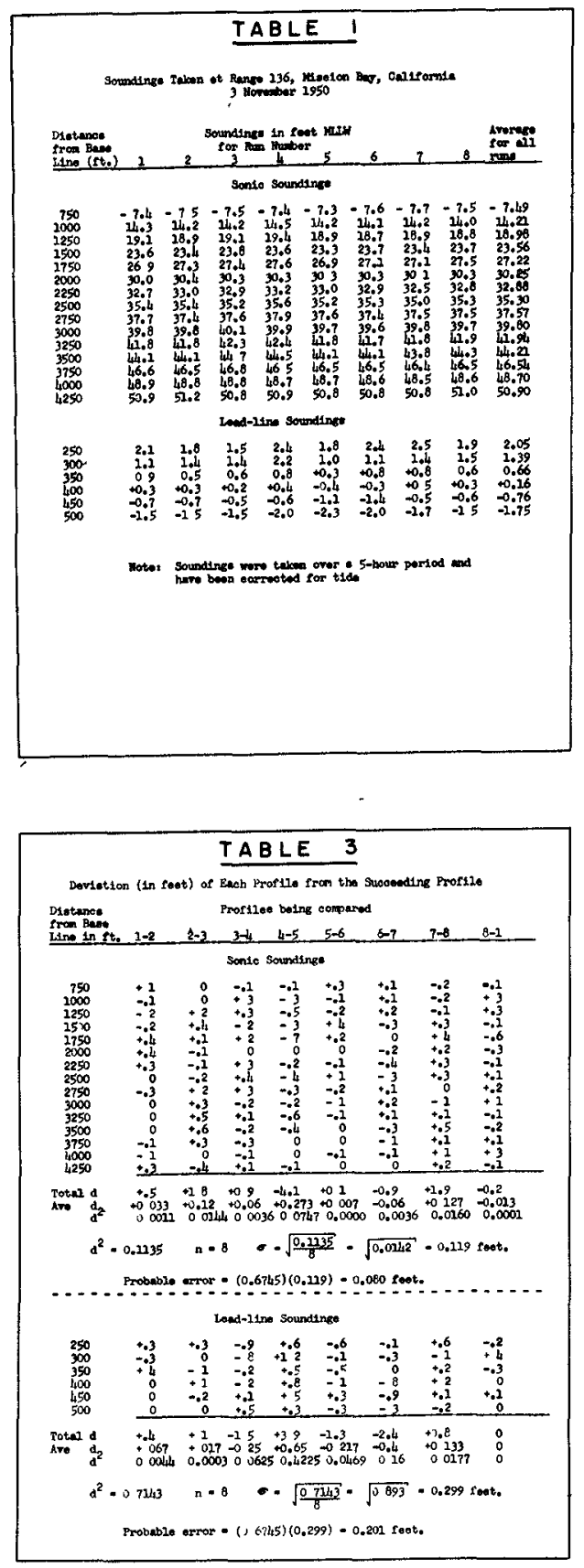
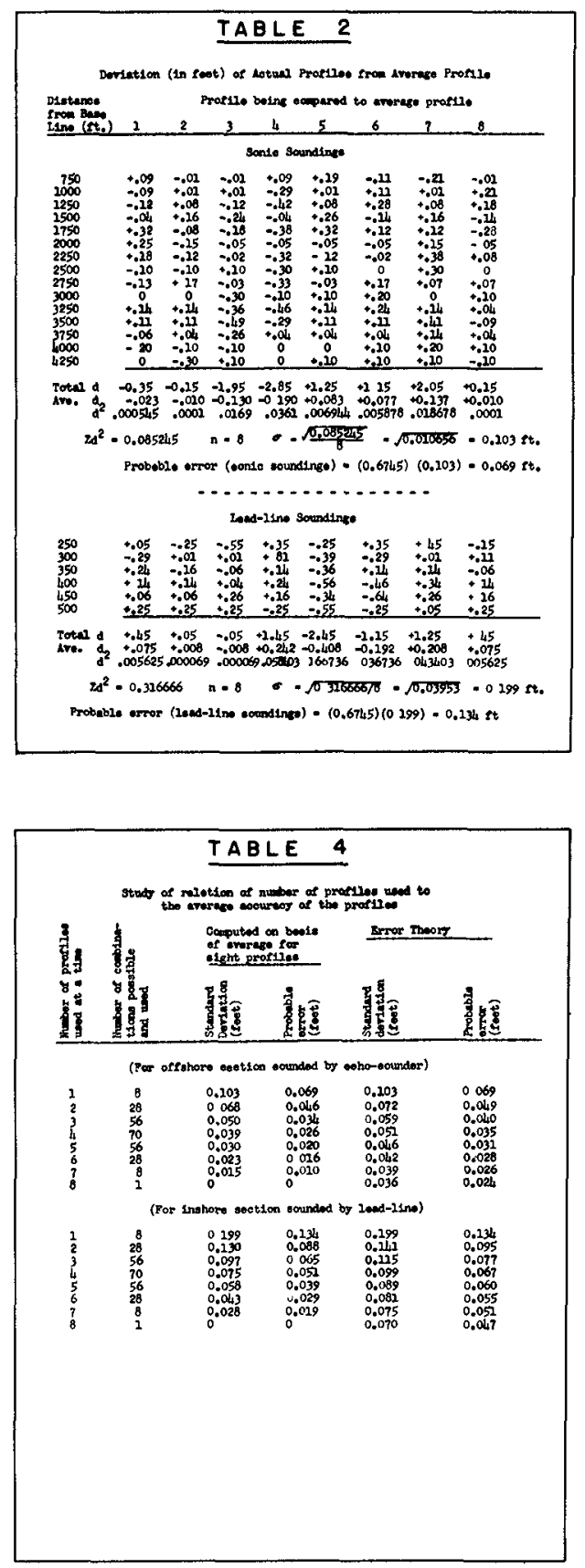


\section{COASTAL ENGINEERING}

The deviation of the individual soundings from the average sounding for the comparable station is shown in Table 2. The deviations for each profile are summarized algebraically on the table; each summation is in turn divided by the number of stations, 15, in order to establish the average deviation, $d$, of the profile from the average profile. This average deviation is a measure of the error that would be introduced in a set of computations by using a single profile instead of the average profile; thus Run 3 gives a profile for the echo-sounder portion of the record which averages 0.130 feet below the average profile. These average profile deviations, $d$, can be handled collectively by the statistical formula

$$
\sigma=\sqrt{\frac{\Sigma \mathrm{d}^{2}}{\mathrm{n}}}
$$

where $a$ is the standard deviation and $n$ is the number of observations. The result is

$$
\sigma=\sqrt{\frac{0.08524}{8}}=0.103 \text { feet }
$$

The probable error, P.E., in any one profile is given by

$$
\text { P.E. }=0.6745^{\circ}=0.069 \text { feet. } \text { (say } 0.07 \text { feet) }
$$

This indicates that any one profile obtained by the echo sounder can be expected to hate an uncompensated error averaging 0.07 feet.

The second method of analysis involves comparing each profile with the succeeding profile. In this manner, no attempt is made to establish the absolute profile as was done with the "average" profile in the preceeding paragraph; rather the comparison is on the basis of the comparability of successive profiles. The statistical analysis based on this reasoning is given in Table 3. In this case it can be seen that the profile of Run 1 is compared to Run 2, then Run 2 to Run 3, and so on. Finally, Run 8 is compared back to Run 1, The summation and statistical handling is the same as used previously and shows for the echo-sounder portion of the record a standard deviation, $\sigma$, of 0.119 feet, and a probable error of 0.08 feet. It is to be noted that the probable error indicated by this analysis is of the same order as for the first analysis $(0.08$ feet against 0.07 feet $)$. Attention is also called to the fact that the deviation for the comparison of Run 8 to Run 1 was well below the average deviation, indicating that there was no systematically increasing error over the 5-hour test period.

In considering this indication of an 0.07 to 0.08 foot uncompensated error it should be kept in mind that this figure is probably an optimistic one due to the fact that the comparative profiles were taken on the same day with the same personnel and equipment and with a relatively small tide variation. These factors would tend to make the error somewhat less than would be the case if the surveys were taken several weeks or months apart. Also, any constant error that might have been effective on the day of the soundings, such as in the instruments, the submergence of the 
sounder, or the tide adjustment, is not included in the 0.07 foot figure. ANALYSIS OF LEAD-LINE SOUNDING DATA

A lead-line was used for sounding whenever the wheels of the DUKW were grounded. Table 1 shows the lead-line soundings as well as the sonic soundings taken during the running of the eight test profiles. These soundings were analyzed statistically in the same manner as the echo sounder records and it was found that:

(a) A comparison of profile deviation against the "average" profile showed an uncompensated probable error of 0.13 feet.

(b) A comparison of successive profiles showed an uncompensated probable error of 0.20 feet.

It is seen that these probable errors with the lead-line are considerably greater than the probable errors for that portion of the profile sounded by echo sounder. However, the portion of the profile covered by lead-line is generally a minor portion of the entire profile so that the quantitative error is usually not as great in the overall picture. In the Mission Bay tests, about 4,000 feet of profile was sounded by echo sounder and about 300 feet by lead-line.

The fact that the actual beach profile for the eight test runs was probably slightly different for each run is appreciated. However, this does not change the analysis given above, as no hydrographic survey is made simultaneously over all profiles. Instead the profiles are run successively as in the test and the test runs would appear to indicate the degree of comparability of the profiles, which was the purpose of the test.

Of some significance in considering the results of the analysis given above is the fact that the portable echo-sounders used in most beach profile work are rated as having an accuracy of $\pm \frac{1}{2}-$ foot at a 50foot depth. It should be noted that the sounder accuracy is expressed in feet at 50 feet and not as a percentage; this is done because some of the errors in the sounder vary with depth whereas others are independent of depth. Thus the error could be expected to be less at 10 feet than at 50 feet but not as much less as the ratio of depths might indicate. The fact that during the eight test runs discussed above the same echosounder was used by the same crew and the entire test covered only a 5hour period would tend to hold the sounder error to a minimum. The usual bar checks were made to adjust the sounder before starting the tests.

\section{APPLICATION TO A SURVEY CONSISTING OF MORE THAN ONE PROFIIE}

The preceding discussion applies to the sounding error to be expected over a single profile. Most hydrographic surveys involve the use of a number of profiles to determine the hydrography of a given area. The use of multiple profiles makes it likely that the uncompensated errors in one profile will be somewhat compensated by a similar error opposite in sign 


\section{COASTAL ENGINEERING}

on another profile. The eight profiles used in the preceding discussion were accordingly analyzed toward the end of discovering the sounding error to be expected in the use of multiple profiles.

In making this analysis, the eight profiles of Table I were compared to the average profile shown in the same table. The eight profiles were compared individually to the average and the resultant deviations compared statistically; the results of this comparison have already been discussed and are shown on Table 2. The results indicated for the sonic-sounder portion a standard deviation of 0.102 feet based on the use of a single profile on which to establish a comparison.

The indicated errors for every possible combination of two profiles were then averaged. The results established a standard deviation for the offshore portion of 0.0676 feet based on the use of two profiles. The comparison was continued for all possible combinations of three, four, five, six, seven, and eight profiles with the results shown in Table 4. In using these results, two factors must be kept in mind:

(1) That the results should not be construed as indicating to what degree the profiles are representative of the section of beach which they are assumed to represent. The present portion of this memorandu is pointed toward indicating the "surveying" errors; the degree to which a selected profile may be considered representative will be discussed later in this memorandum.

(2) That the entire set of computations is influenced by the fact that only eight profiles were used and that these eight were averaged to give the reference or base profile. This condition effects the lower end of the curve much more than the upper end; for instance Table 4 indicates a zero deviation if eight profiles are used, which is obviously unrealistic. However, it is believed that the figures for the use of one or two profiles are not too greatly influenced by the fact that only eight profiles were used as a basis for the computations.

If the value based on the use of the single profiles is assumed to be correct, then values for the use of any number of profiles may be derived from error theory, to give

$$
\sigma_{n}=\frac{\sigma_{1}}{\sqrt{n}}
$$

where $\sigma_{n}$ represents the standard deviation to be expected from the use of $n$ profiles; and $\sigma_{1}$ is the standard deviation for a single profile. $\sigma_{1}$ was previously shown to be 0.103 feet for the sonic portion of the profile and 0.199 for the lead-line portion. Values for the probable error may be derived similarly, and

$$
P \cdot E \cdot n=\frac{P \cdot E \cdot I}{\sqrt{n}}
$$

Values for the standard deviation and probable error computed by this 


\section{ACCURACY OF HYDROGRAPHIC SURVEYING IN AND NEAR THE SURF ZONE}

\begin{tabular}{|c|c|c|c|c|c|c|c|}
\hline \multirow{4}{*}{$\begin{array}{l}\text { Number of } \\
\text { Profiles used }\end{array}$} & \multicolumn{6}{|c|}{ TABLE 5} & \\
\hline & \multicolumn{7}{|c|}{ Probable Sounding Errors in Beach Surveys liade with Sonze Sounder } \\
\hline & \multirow{2}{*}{$\begin{array}{c}\text { Standard } \\
\text { deviation } \\
\text { (foet) }\end{array}$} & \multirow{2}{*}{$\begin{array}{l}\text { Probable } \\
\text { error } \\
\text { (feet) }\end{array}$} & \multirow{2}{*}{$\begin{array}{l}\text { Probable } \\
\text { using pro } \\
\text { Ift. }\end{array}$} & \multirow{2}{*}{$\begin{array}{l}\text { rror in cu } \\
11 \text { enth } \\
100 \text { 1t. }\end{array}$} & $\begin{array}{l}\text {. yd. ner } \\
\text { an average }\end{array}$ & $\begin{array}{l}\text { linear foot } \\
\text { length of }\end{array}$ & \multirow{2}{*}{$\begin{array}{l}\text { shore, when } \\
5000 \mathrm{ft} \\
\end{array}$} \\
\hline & & & & & $500 \mathrm{rt}$. & $1000 \mathrm{ft}$. & \\
\hline 1 & 0.103 & 0.069 & 0.00255 & 0.255 & 1.27 & 2.55 & 12.7 \\
\hline$\frac{1}{2}$ & 0.072 & 0.049 & 0.00182 & 0.182 & 0.91 & 1.82 & 9.1 \\
\hline 3 & 0.059 & 0.040 & 0.00148 & 0.148 & 0.74 & 1.48 & 7.2 \\
\hline 4 & 0.0510 & 0.0342 & 7.00127 & 0.127 & 0.63 & 1.27 & 6.3 \\
\hline$\frac{4}{5}$ & $0.01,57$ & 0.0308 & 0.00114 & 0.114 & 0.57 & 1.14 & 5.7 \\
\hline 6 & 0.0418 & 0.0280 & 0.00104 & 0.104 & 0.52 & 1.04 & 5.2 \\
\hline 8 & 0.0361 & 0.0243 & 0.00090 & 0.090 & 0.45 & 0.90 & 4.5 \\
\hline 10 & 0.0321 & 0.0217 & 0.00080 & 0.080 & 0.40 & 0.80 & 4.0 \\
\hline 15 & 0.0264 & 0.0177 & 0.00066 & 0.066 & 0.33 & 0.66 & 3.3 \\
\hline 20 & 0.0229 & 0.0154 & 0.00057 & 0.057 & 0.29 & 0.57 & 2.0 \\
\hline 30 & 0.0186 & 0.0126 & 0.00047 & 0.047 & 0.23 & 0.47 & 2.3 \\
\hline 40 & 0.0161 & 0.0110 & 0,00047 & 0.041 & 0.20 & 0.211 & 2.0 \\
\hline 50 & 0.0145 & 0.0097 & 0.00036 & 0.036 & 0.18 & 0.36 & 1.8 \\
\hline 75 & 0.0118 & 0.0079 & 0.00029 & 0.029 & 0.15 & 0.29 & 1.5 \\
\hline 100 & 0.0102 & 0.0069 & 0.00026 & 0.026 & 1.13 & 0.26 & 1.3 \\
\hline 150 & 0.0084 & 0.0056 & 0.00021 & 0.021 & 0.10 & 0.21 & 1.0 \\
\hline 200 & 0.0072 & 0.0049 & 0.00018 & 0.018 & 0.09 & 0.18 & 0.9 \\
\hline 500 & 0.0046 & 0.0031 & 0.00011 & 0.011 & 0.06 & 0.11 & 0.6 \\
\hline 1000 & 0.0032 & 0.0022 & 0.00008 & 0.008 & 0.04 & 0.08 & 0.4 \\
\hline
\end{tabular}

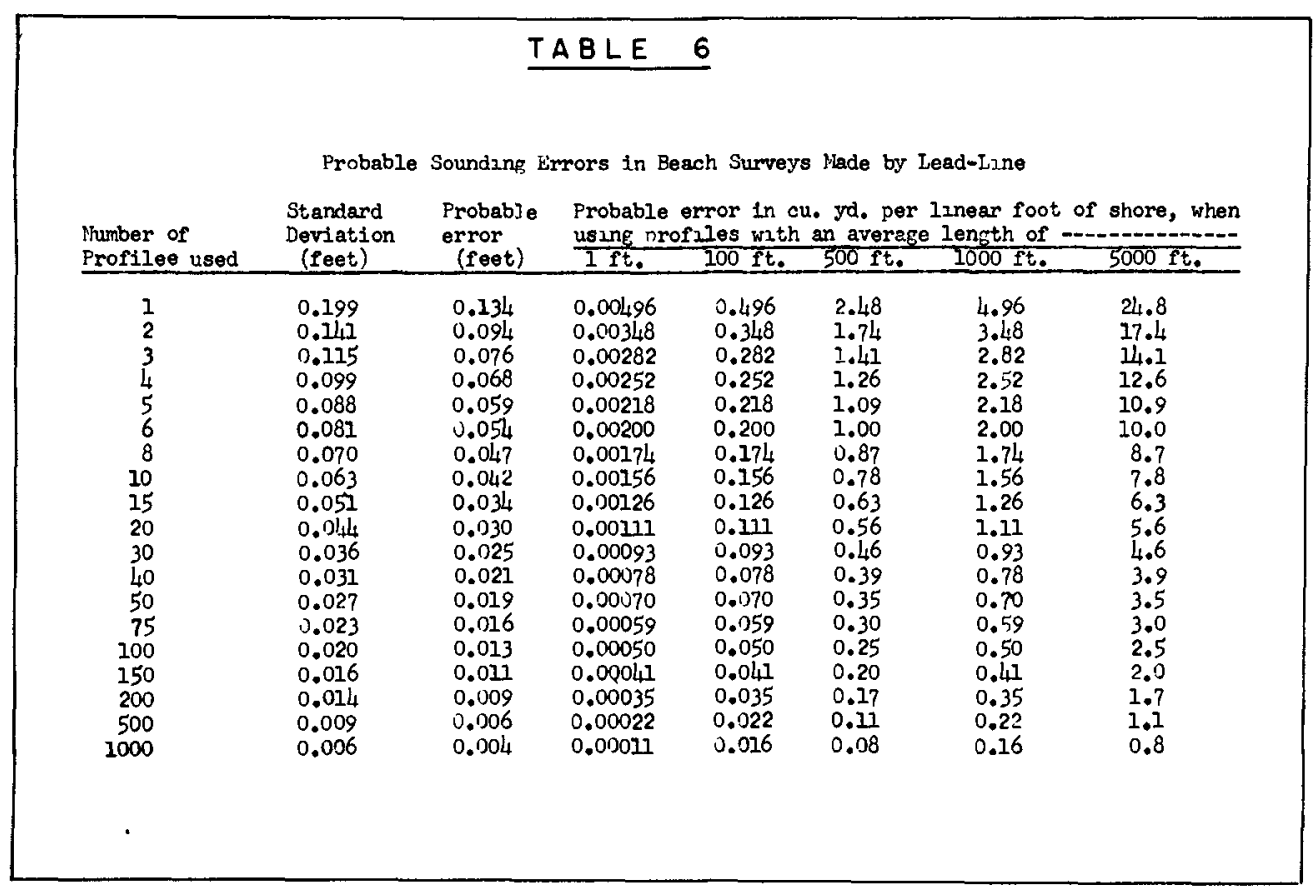




\section{COASTAL ENGINEERING}

formula are also shown in Table 4. Figure 1 shows the variation of the sounding error as computed by error theory if it is assumed that the value for a single profile is correctly obtained from the average of the eight test profiles. Also shown are the points obtained from using all the possible combinations of the test profiles for the sonic portion of the test. As may be seen the points obtained for the combination of two and three profiles do not differ greatly from the error theory curve, and this supports strongly the assumption that the value for the single profile is very nearly correct.

The data from Figure 1 have the dimensions of feet, and can be expressed as cubic feet per lineal foot of shore per foot of profile and hence can be reduced to a relationship of probable cubage error per foot of shore as related to the number of profiles utilized in the survey under consideration. A tabulation of this relationship for the sonic sounder, as computed from Figure 1 , is given in Table 5, and for lead-line soundings in Table 6. The relationships for both lead-line and sonic portions are shown as a series of curves in Figure 2. The values given in Tables 5 and 6 or Figure 2 are readily applied to the analysis of the probable surveying error inherent to a given survey of a beach. Knowing the number of profiles used, and the average length of these profiles, the cubage error per foot of beach can be computed. The product of this unit error and the length of beach gives the probable cubage error over the study area. It should be kept in mind that the cubage errors indicated in Tables 5 and 6 are per linear foot of beach. As an example, for a 10,000 foot section of beach, surveyed by 20 profiles each 4,000 feet long, the total probable sounding error would be $(0.57)(4)(10,000)-22,800$ cubic yards.

From the above it can be seen that surveying errors may enter the analysis of a beach problem to a significant degree if too few profile lines are used in the study. It should again be emphasized that these errors represent "sounding exror" alone and take no account of a spacing error.

It should be noted that the computations discussed above and tabulated in Tables 2 and 4 were based on the use of fifteen soundings for the sonic sounder section of each profile. The question arises as to the effect on the comparative accuracy of the profile line of increasing the number of soundings. This effect was investigated by taking the same eight profiles previously used and picking off soundings at 125-foot intervals instead of 250-foot intervals; this resulted in thirty soundings for comparison, or double the number originally used. An intercomparison of these eight profiles with thirty soundings each was then worked out on the same basis as described above. Table 7 shows a comparison of the results using 30 soundings per profile with the results using 15 sounding per profile; the very close agreement in the results indicates that the use of 15 soundings per line was sufficient to establish the accuracy characteristics of the profile and that nothing would be gained by increasing the number of soundings utilized in the comparison. 


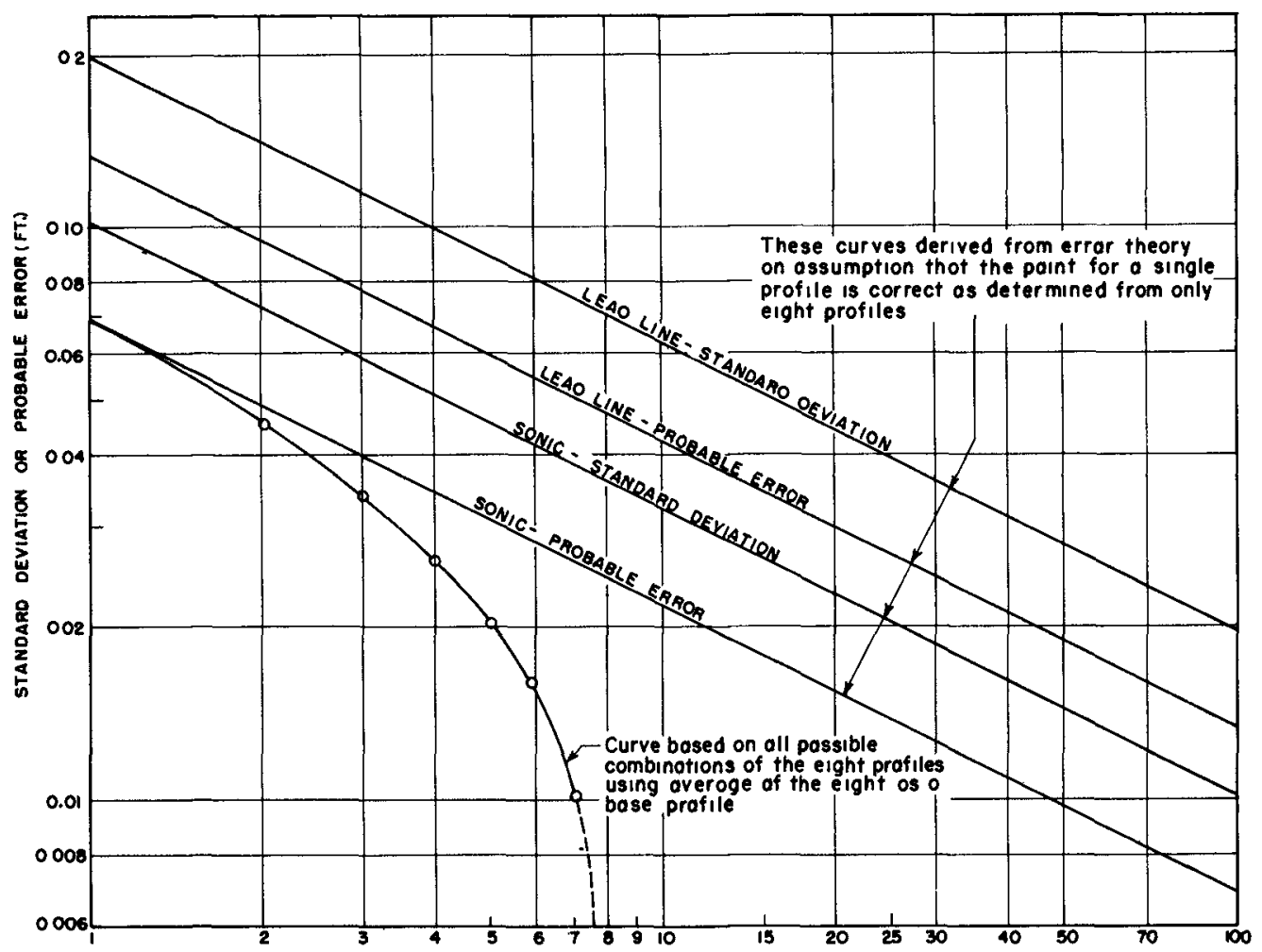

Fig. 1. Variation of sounding error with number of profiles sounded.

TABLE 7

Study of Effect of Number of Soundings per Proftle on the Average Accuracy of a Profile

Number of profiles used at a time
Standard deviatzon* in feet using 15 soundings 30 soundings per profile per profile

$\begin{array}{ll}0.103 & 0.103 \\ 0.0676 & 0.0675 \\ 0.0504 & 0.0503 \\ 0.0302 & 0.0302 \\ 0.0225 & 0.0224 \\ 0.0147 & 0.0147\end{array}$

* In computing these deviations, the various profiles and combinations were compared to the average profile of the eight profiles as was done in Tables 2 and 4. When succeeding profiles were compared in the manner done in Tables 3, the use of 30 soundings per profile showed a standard deviation of 0.0118 feet which is identical with the results show in Table 3 for 15 soundings per profile. 


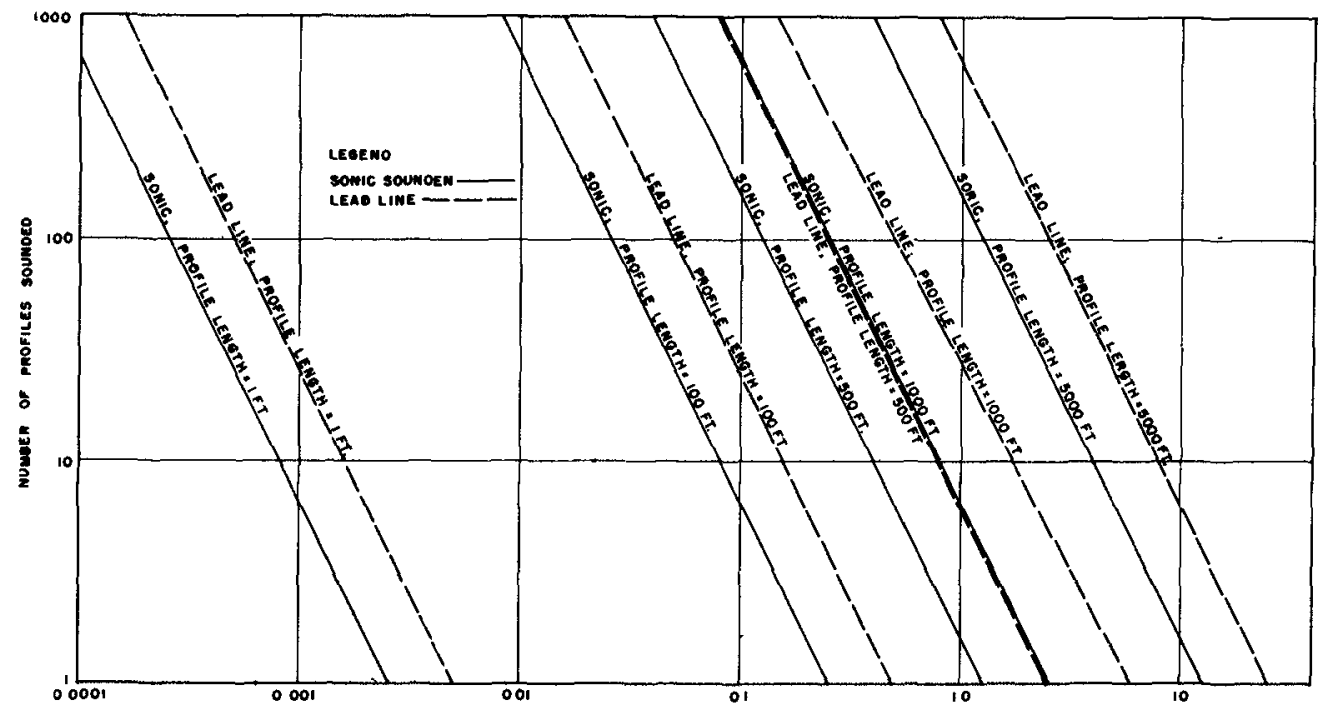

Fg. 2. Rolation of probable sounding error in a beach surrey to the number of profiles sounded for difforent profile lengths (doos not include pacing orror).

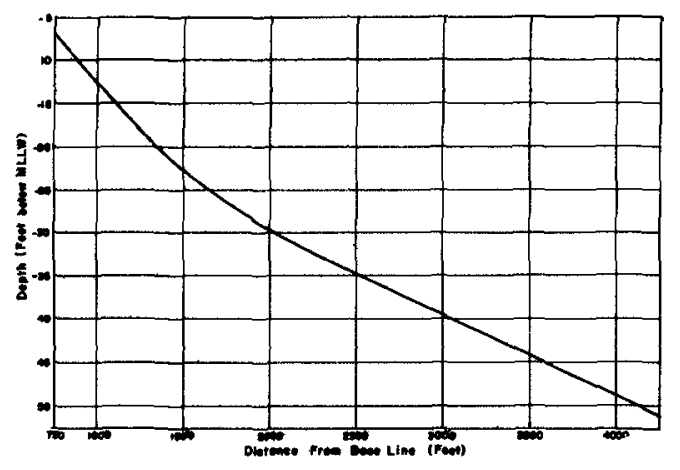

Hg. 3a. Arorage profile for ontire tost section 9 June 1950 (sonio data).

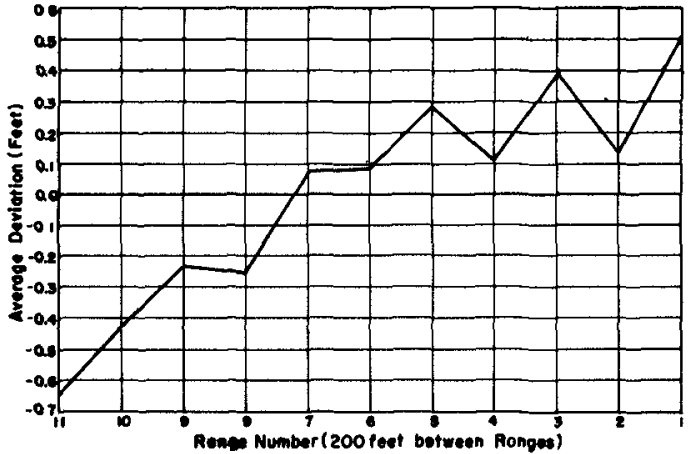

Flg. 3b. Averago deviation of each profile from the averago profile for the entire test seotion, 9 June 1950 (sonio data). 


\section{DETERMINATION OF THE SPACING ERROR}

\section{DESCRIPTION OF TEST}

As stated in the introduction, the spacing error is considered as the error resulting from the fact that a particular profile may not be entirely representative of its assigned section of beach. The tests to determine spacing error involved the use of data obtained from two different sets of surveys. These were:

(a) The sounding at Mission Beach of a 2,000-foot test section consisting of eleven ranges spaced two hundred feet apart at approximately one week intervals between $12 \mathrm{May}$ and 8 September 1950. In addition, three surveys were made in April 1951, making a total of nineteen surveys. The ranges involved were established by the Field Research Group of the Beach Erosion Board in connection with other work, and were designated Beach Erosion Board ranges 126-146. The mid-range of the section was about 5,500 feet north of the Mission Bay jetties and the -50 -foot contour is about 4,250 feet of fshore. All surveys extended from the shore line to the -50 -foot mean lower low water contour.

(b) The sounding at Mission Beach of a 9,200-foot section of beach consisting of 47 ranges spaced two hundred feet apart at approximately three month intervals between June 1949 and April 1951. A total of eight surveys were involved. Again, all surveys extended to the -50 -foot mean lower low water contour. The ranges involved were Beach Erosion Board ranges 78-170; range 170 is about 2,100 feet north of the Mission Bay jetties; range 78 is slightly over two miles north of the jetties, and about 2,000 feet south of Crystal Pier.

The entire beach in the Mission Beach area is sand and has essentially straight and parallel contours, with no radical changes in underwater hydrography along its length; this uniformity of the beach was considered desirable for this study as the profiles might reasonably be expected to be representative of an extensive section of beach.

\section{ANALYSIS OF THE ECHO SOUNDER DATA}

The echo sounder data and the lead-line soundings were analysed separately. The echo sounder charts were corrected for tide elevation, and as in the analysis for "sounding error", soundings were taken of $f$ at 250-foot intervals along each range starting from a point 750 feet from the baseline. A tabulation of the soundings of the eleven profiles for the 2,000-foot test section for the survey of 12 May 1950 is shown in Table 8 , as is an "average" profile obtained by averaging the eleven separate profiles. The deviation of any particular profile from this "average" profile is a measure of the error involved if only that profile were used to determine the hydrography of the area. Similarly, the error involved in using any particular set of profiles to indicate this hydrography may be measured as the sum of the deviations of the profiles from the average profile, if these deviations are weighted according to the area which each profile is assumed to represent. For the 12 May 1950 survey of the 2,000-foot test section, a tabulation of the deviation of 


\section{COASTAL ENGINEERING}

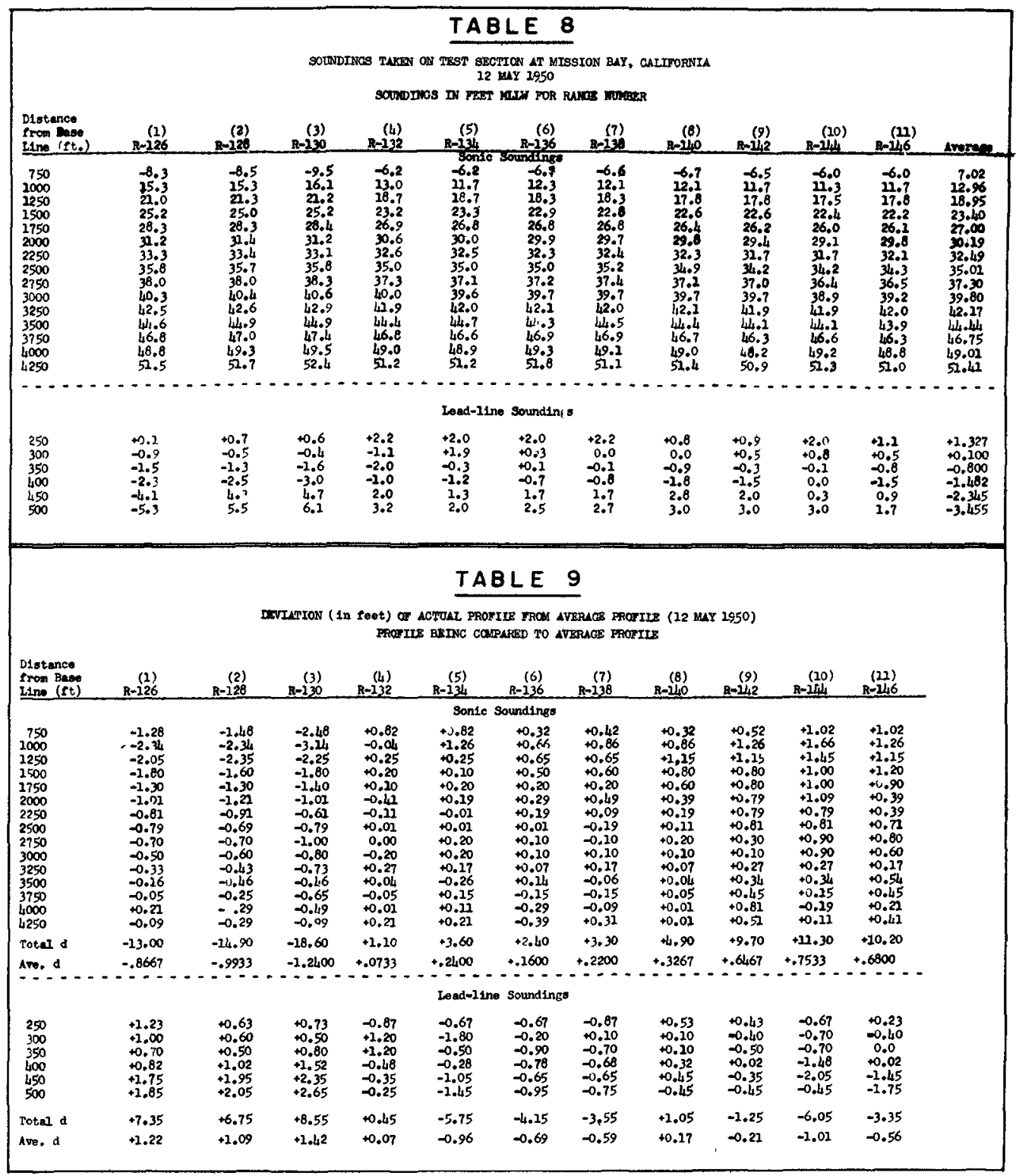



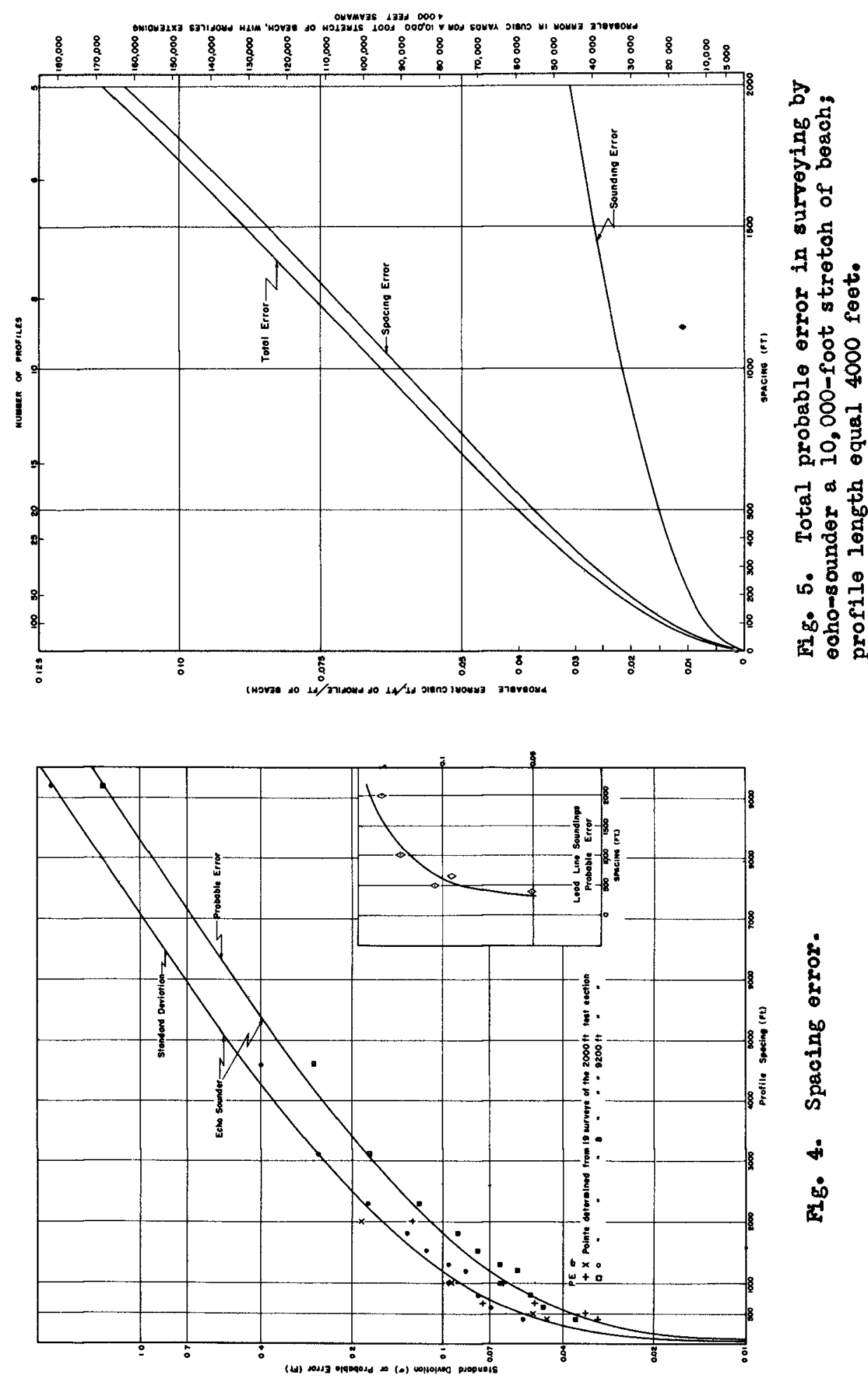


\section{COASTAL ENGINEERING}

each sounding and the overall deviation of each range from the average profile is shown in Table 9. Similar tabulations were made for each of the nineteen surveys of the 2,000-foot test section and each of the eight surveys of the 9,200-foot section. Figure 3 shows a typical average profile, and the average deviation of each individual profile from this average profile.

The error involved in using a number of different combinations of profiles rather than the full number of profiles was determined for each survey. The combined error for a series of evenly spaced profiles was determined as the algebraic sum of the deviations of e ach individual profile from the average profile determined from full survey data. This gave a variation of profile spacing of 400 to 2,000 feet for the test section and 400 to 9,200 feet for the full section. A tabulation of these errors (for the combinations of profiles selected) for the test section surveys is shown in Table 10, and for the full section survey in Table 11. The nineteen different values (one for each survey) involved in the test section and the eight different values involved in the full survey may be analyzed statistically to obtain a standard deviation and a probable error by the formulae used in the preceding section, and these values are also shown in Tables 10 and 11 .

Several of the combinations of profile lines used have the same spacing, and these may be combined to give a single value of the standard deviation for each spacing. For example, in the test section, using a combination of ranges 3 and 9 gives a 1,000-foot spacing, as does also the combination of ranges 1,6 , and 11. The former results in a probable error of 0.072 and the latter in one of 0.053 . These may be combined by taking the square root of the sum of the squares to give a single, more accurate value of 0.064 for the probable error. This combining has been done for both the test section and the full survey, and values of standard deviation and probable error for the various spacings are shown in Table 12. These values have been plotted in Figure 4, and curves drawn to fit the points. The scatter is surprisingly small, and it is thought that the curve represents fairly accurately the error which may be expected due to profile spacing on beaches having a hydrography generally similar to that of Mission Beach and sounded by sonic methods.

Due to the large number of surveys and profiles used, the sounding error (discussed previously) is negligible (each point plotted represents the results from the combination of a minimum of 57 profiles, and most points are obtained from several hundred profiles) -- and hence the error determined by this method may be attributed entirely to spacing error. This source of error is of greater magnitude than the sounding error, and may reach considerable values if the spacing is 1 arge.

That portion of the curves for spacingsetween 100 and 2,500 feet may be represented very closely by the linear functions

$$
\sigma .0 .02+7.2 \mathrm{~s} \times 10^{-5}
$$

and

$$
\text { P. E. }=0.013+4.845 \times 10^{-5}
$$


ENVIRONMENTAL ASPECTS OF THE EBB SIDE AND FLOOD SIDE OF TIDAL ESTUARIES AS A FACTOR IN HARBOR LOCATIONS

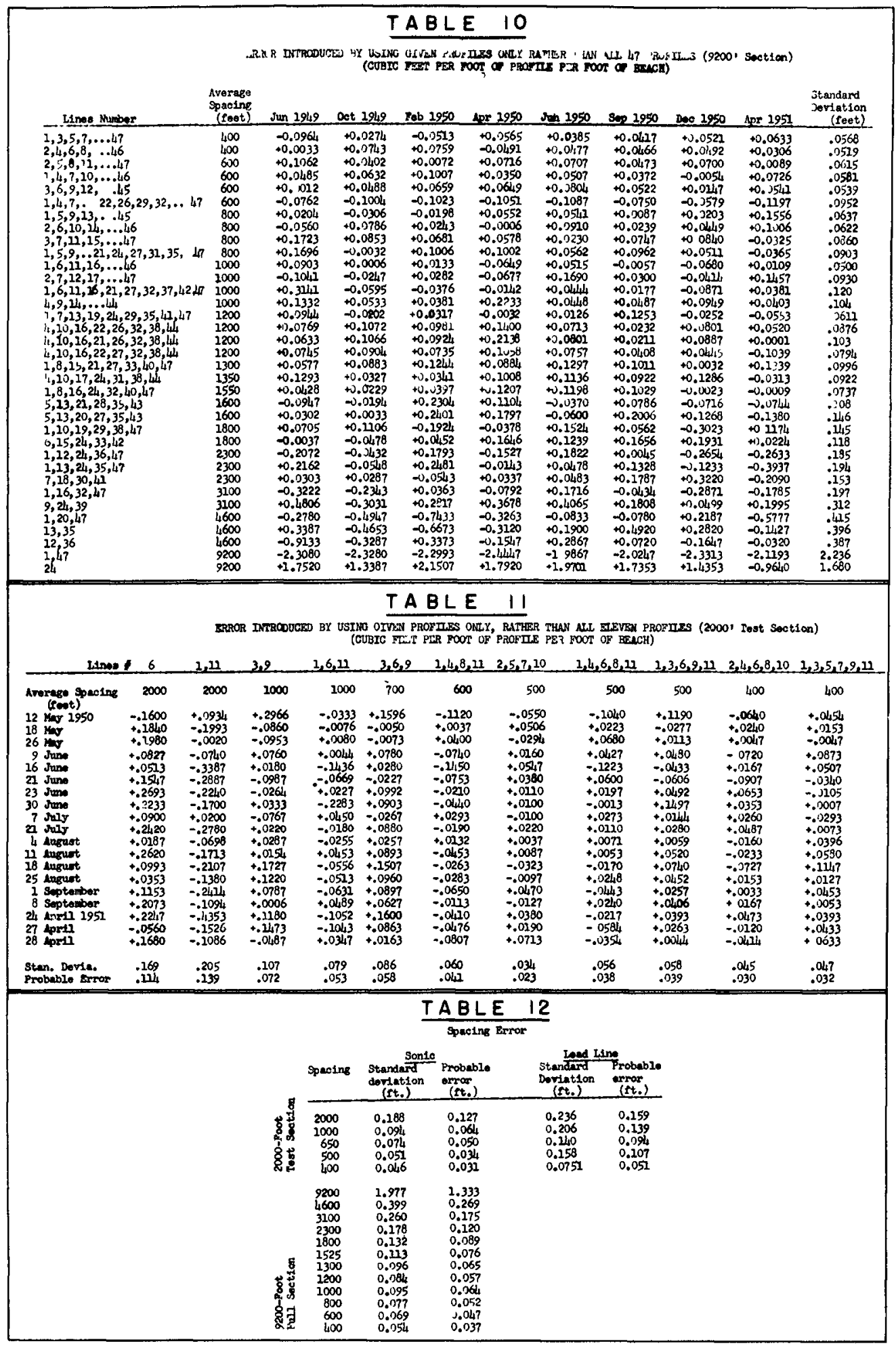




\section{COASTAL ENGINEERING}

where $s$ is the spacing in feet.

It was suspected that the spacing error might decrease somewhat as the number of profiles at that spacing was increased -- the spacing error between one set of profiles tending to compensate somewhat for the spacing error between the next set of profiles. If this were true, then the points obtained from the 9,200-foot section, having many more profiles, should lie somewhat beneath the points determined from the 2,000foot test section. Such is not the case however, and it is thought that the curve shown is an accurate portrayal of the spacing error.

\section{ANALYSIS OF LEAD-LINE DATA}

A similar analysis was performed on the lead-line data for the 2,000foot test section. The points determined are also shown in Table 12 and are plotted on Figure 4, whe re a curve of best fit has been drawn in. As with the sonic data the number of profiles used to determine the points is lerge, and the sounding error is therefore negligible. The analysis for the lead-line data for the full 9,200-foot section has not yet been completed, and with the relatively small number of points used to determine the curve, it is not thought that as complete reliance should be placed in this curve as in that for the echo-sounder data.

It may be noted that the apacing error as determined from the leadline data is larger than (roughly twice) that determined from the sonic data. This if, of course, not due to the different methods of surveying, but to the fact that the inshore portion of the beach (where the leadline data was taken) is much less regular than the offshore portion, and a particular profile there would be expected to be much less representative of the surrounding area than it would farther offshore where the hydrography is more regular.

\section{APPLICATION TO ACTUAL SURVEY}

The total error to be expected in any particular survey will be a combination of the sounding error and the spacing error, and may be determined, for beaches similar in hydrography to Mission Beach, from the curves shown herein. If e denotes the total probable error, $e_{s}$ the probable spacing error, and $e_{a}$ the sounding error, then

$$
e=\sqrt{e_{a}^{2}+e_{s}^{2}}
$$

and the probable yardage error is

$$
E=\frac{\sqrt{\left(e_{a}^{2}+e_{s}^{2}\right)} \mathbf{L}^{\prime}}{27}
$$

where $L$ is the length of the beach in feet and $L$ ' the length of the profile in feet.

An example of the combined error for a 10,000-foot stretch of beach is shown in Figure 5. As may be readily seen, the probable error for a 


\section{ACCURACY OF HYDROGRAPHIC SURVEYING IN AND NEAR THE SURF ZONE}

large spacing reaches a quite considerable cubage. It is interesting to note that, at least for this particular case, while the sounding error is quite appreciable, it is so small in comparison to the spacing error that it has only a relatively small effect on the total error.

The above analysis appears to demonstrate that the cubage errors -due to the fact that profiles of a hydrographic survey are not strictly comparable either among themselves or to a previous survey (sounding error), and that any particular profile does not necessarily represent accurately the bottom area which it is assumed to describe (spacing error) -- can introduce serious misinterpretations as to the rate and direction of movement of littoral drift. For Instance, in the Mission Bay area, for a 10,000-foot stretch of beach, it is seen that for a very small range spacing (200 feet) an error of almost 35,000 cubic yards can still be more or less expected in the cubage computations; while for the relatively large spacing of 1,000 feet, an error of almast 100,000 yards can be expected. In many beach s tudies errors of these magnitudes could produce completely misleading interpretations of the test data. It is therefore recommended that the presence of such errors be considered as a distinct possibility in the interpretation of test data based on the comparison of successive hydrographic surveys. 